\title{
Development of open-field activity in the rat following caudate lesions in infancy*
}

\section{DAVID A. JOHNSON and THOMAS M. BECKER Ohio University, Athens, Ohio 45701}

Lesions at the head of the caudate nucleus resulted in increased levels of activity in the open field. Hyperactivity was similar regardless of the animals' age at the time the lesion was produced (7 or 77 days of age). Unilateral lesions resulted in higher levels of activity than did bilateral lesions of the caudate nucleus.

Several investigators have recently reported that subcortical lesions in infant animals resulted in permanent behavioral alterations. Following septal lesions (Johnson, 1972; Johnson, Poplawsky, Bieliauskas, \& Liebert, 1972), hypothalamic lesions (Bernardis \& Frohman, 1971, 1972), or caudate lesions (Kling \& Tucker, 1967; Goldman \& Rosvold, 1972; Johnson et al, 1972) in infant animals, behavioral deficits in adult animals have been observed which were similar to deficits produced by the same types of lesions in adult animals. Other investigators (Isaacson, Nonneman, \& Schmaltz, 1968; Kling, 1962, 1965; Schneider, 1970) have suggested that functional recovery may be site specific at subcortical levels. The present study was designed to provide information on the effects of caudate lesions on the development of open-field activity in the rat.

\section{METHOD}

\section{Subjects and Design}

All animals used in this study were male Long-Evans hooded rats from the Ohio University laboratory colony. Each litter of rats was housed in a polycarbonate group cage until 40 days of age. All animals were housed in individual cages from the age of 40 days until the end of the experiment. Food and water were available ad lib in the animal's cage throughout the experiment.

One-third of the male animals from 14 litters received bilateral caudate lesions (Group IBC, $\mathrm{N}=8$ surviving), one-third of the animals received unilateral caudate lesions (Group IUC, $\mathrm{N}=10$ surviving), and one-third of the animals received a bilateral electrode puncture treatment (Group IP, $N=15$ surviving). All operations were performed at 7 days of age.

All animals were observed in the open field at $21,28,35,42$, $49,56,63,70$, and 77 days of age. When developmental observations had been completed (77 days of age), animals in Group IP were subdivided into three groups of five animals each. Five animals were given bilateral caudate lesions (Group ABC), five were given dorsal cortical lesions (Group AC), and five received no additional treatment (Group AP). A 21-day recovery period was allowed before beginning observations again. Animals in Groups IBC and IUC were allowed to remain in their cages with no additional experimental treatment for the 21-day

*This research was supported in part by Ohio University Research Grant 0-21000-3660 and in part by NIMH Grant 1-RO3-MH22158-01 to David A. Johnson. Requests for reprints should be sent to David A. Johnson, Department of Psychology, Ohio University, Athens, Ohio 45701. James L. Bruning sponsors this paper and takes full editorial responsibility for it. period. At the age of 100 days, animals in the original Groups IBC and IUC, as well as the new Groups $A B C, A C$, and IP, were again observed in the open field for $3 \mathrm{~min}$ of observation on 6 successive days.

\section{Surgery}

Caudate lesions in infant animals were placed using procedures similar to those reported by Johnson (1972). Animals were held stationary by a clay mold, fitted to the rat pup's body. The head was held in a horizontal plane, and bregma was used as stereotaxic zero. An electrode, insulated except for $.5 \mathrm{~mm}$ at the tip, was lowered $3.5 \mathrm{~mm}$ ventral from the dorsal cortex at points $\pm 2.0 \mathrm{~mm}$ lateral to the longitudinal sinus at bregma. A $1.5-\mathrm{mA}$ anodal current was passed for $15 \mathrm{sec}$ either unilaterally or bilaterally. Ground was accomplished by taping the animal's tail and feet about the cathode.

Caudate lesions in animals 77 days of age were accomplished using de Groot coordinates (1959) AP $+7.0 \mathrm{~mm}, \mathrm{~L} \pm 2.5 \mathrm{~mm}$, and $\mathrm{DV}+2.5 \mathrm{~mm}$. An anodal current of $2.0 \mathrm{~mA}$ was passed for $20 \mathrm{sec}$ for each lesion. Cortical lesions were placed at coordinates $\mathrm{AP}+7.0 \mathrm{~mm}, \mathrm{~L} \pm 2.5 \mathrm{~mm}$, and $\mathrm{DV}+6.0 \mathrm{~mm}$, using the $2.0-\mathrm{mA}$ current for $20 \mathrm{sec}$.

When the experiment was completed, each animal was anesthesized and perfused intracardially with physiological saline followed by $10 \%$ Formalin. Brains were frozen and 50 -micron sections were collected and stained with cresyl violet.

\section{Procedure}

At the ages of $21,28,35,42,49,56,63,70$, and 77 days and at the ages of 100-105 days, each animal was placed in a Latane (1969) open field for a 3-min period daily and activity levels were recorded. The field was divided into 49 equal area sections. Activity was measured in terms of number of sections entered by an animal (all four feet in an adjacent section).

\section{RESULTS}

Caudate lesions of animals in Groups IBC, IUC, and $\mathrm{ABC}$ were about $1.5 \mathrm{~mm}$ in diam and located about $3.0 \mathrm{~mm}$ lateral to the columns of the fornix, about midway between the internal capsule and the arm of the corpus callosum. Caudate damage produced at 7 days of age or 77 days of age was comparable. Caudate lesions produced at 77 days of age also involved some minor neocortical damage which was not detectable in any of the lesions produced at 7 days of age. The neocortical lesions in Group AC were relatively small (about $1 \mathrm{~mm}$ in diam) bilateral lesions located dorsal to the caudate areas destroyed in Groups IBC and IUC.

When the development of open-field activity level of animals in Groups IBC, IUC, and IC was compared, animals with caudate lesions were more active than control animals $(\mathrm{F}=3.86, \mathrm{df}=2 / 30, \mathrm{p}<.05)$. Animals in Group IUC were more active than animals in other groups (mean activity level $52 \mathrm{sq} / 3 \mathrm{~min}$ ), while animals which received bilateral caudate lesions at 7 days of age were intermediate in activity level $(36 \mathrm{sq} / 3 \mathrm{~min}$, Group IBC). Animals in Group IC ( $25 \mathrm{sq} / 3 \mathrm{~min})$ were lowest in open-field activity (see Fig. 1). 


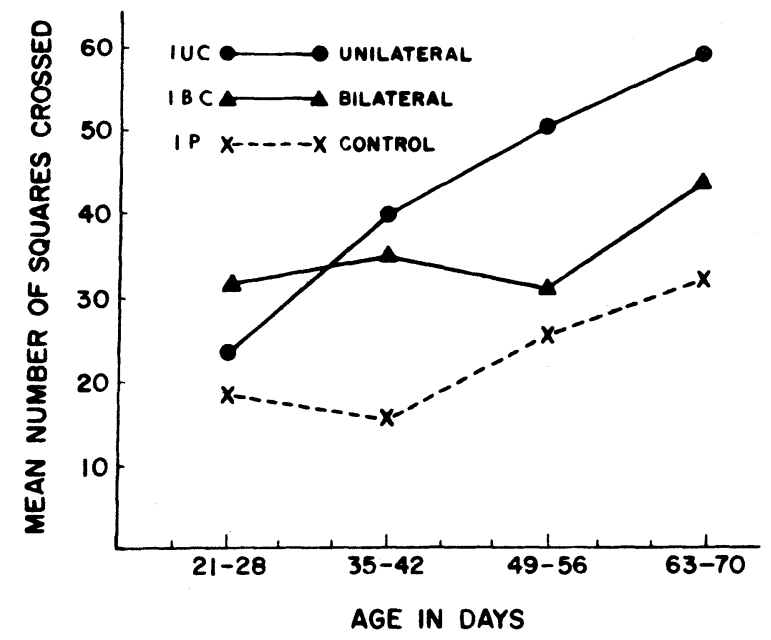

Fig. 1.

Table 1

Mean Number of Open-Field Sections Crossed in a 3-Min Period for Animals Receiving Caudate Lesions at 7 or 77 Days of Age: 100-105 Days of Age at Time of Observation

\begin{tabular}{lccccc}
\hline & \multicolumn{5}{c}{ Groups } \\
\cline { 2 - 6 } & IUC & IBC & IP & ABC & AC \\
& $\mathrm{N}=10$ & $\mathrm{~N}=8$ & $\mathrm{~N}=5$ & $\mathrm{~N}=5$ & $\mathrm{~N}=5$ \\
\hline $\begin{array}{c}\text { Activity } \\
\text { Scores }\end{array}$ & 61.3 & 51.2 & 26.7 & 54.1 & 21.3 \\
\hline
\end{tabular}

At 100 days of age, large differences in open-field activity were again observed between animals in Groups IBC, IUC, $A B C, A C$, and IP $(F=8.58, d f=4 / 28$, $\mathrm{p}<.01)$. Animals in Group IUC were still the most active, while animals which received bilateral caudate lesions at both 7 and 77 days of age displayed an intermediate level of activity. Animals with a puncture treatment in infancy or puncture in infancy plus small dorsal neocortical lesions at 77 days of age did not differ from each other in activity level and were less active than animals in all other groups.

\section{DISCUSSION}

This study provides further evidence that caudate lesions produced in infant animals have lasting behavioral effects. Previous studies (Goldman \& Rosvold, 1972; Johnson et al, 1972) also have revealed incomplete recovery following caudate damage in infant animals. This study, along with other studies cited in the introduction, support a hierarchical concept of recovery of function. The capacity to recover from subcortical damage in infancy seems more limited than the capacity to recover from restricted neocortical lesions in infancy.

\section{REFERENCES}

Bernardis, L. L., \& Frohman, L. A. Effects of lesion size in the ventromedial hypothalamus on growth hormone and insulin levels in weanling rats. Neuroendocrinology, 1970, 6, 319-328.

Barnardis, L. L., \& Frohman, L. A. Effects of hypothalamic lesions at different loci on development of hyperinsulinemia and obesity in the weanling rat. Journal of Comparative Neurology, 1971, 141, 107-115.

deGroot, J. The rat forebrain in stereotaxic coordinates. Amsterdam: N. V. Moord-Hollandsche Vitgevers Maatschappy, 1959 $52,1-40$.

Goldman, P. S., \& Rosvold, H. E. The effects of selective caudate lesions in infant and juvenile rhesus monkeys. Brain Research, $1972,43,53-66$

Isaacson, R. L., Nonneman, A. J., \& Schmaltz, L. W. Behavioral and anatomical sequelae of damage to the infant limbic system. In R. L. Isaacson (Ed.), The neuropsychology of development: A symposium. New York: Wiley, 1968. Pp. 41-78.

Johnson, D. A. Developmental aspects of recovery of function following septal lesions in the infant rat. Journal of Comparative \& Physiological Psychology, 1972, 78, 331-348.

Johnson, D. A., Poplawsky, A., Bieliauskas, L., \& Liebert, D. Recovery of function on a two-way conditioned avoidance task following septal lesions in infancy: Effects of early handling. Brain Research, 1972, 45, 282-287.

Kling, A. A mygdalectomy in the kitten. Science, 1962, 137 , 429 .

Kling, A. Behavioral and somatic development following lesions of the amygdala in the cat. Journal of Psychiatric Research, 1965, 3, 263-273.

Kling, A., \& Tucker, T. J. Effects of combined lesions of frontal granular cortex and caudate nucleus in the neonatal monkey. Brain Research, 1967, 6, 428-439.

Latane, B. Gregariousness and fear in laboratory cats. Journal of Experimental Social Psy chology, 1969, 5, 61-69.

Schneider, G. E. Mechanisms of functional recovery following lesions of the visual cortex or superior colliculus in neonate and adult hamsters. Brain Behavior \& Evolution, 1970, 3 , 295-323.

(Received for publication February 21, 1973.) 